\title{
Polisemia
}

\section{LO FEMENINO: UNA PO-ÉTICA}

Aída Sotelo Céspedes $^{2}$

\section{Resumen}

E I artículo pretende dar cuenta de la experiencia de lo femenino del sujeto, como instancia de la cual surgen el acto ético y el acto creativo. Para hacerlo requiere distinguir al individuo del sujeto del significante y ubicar la alteridad del ser de goce respecto al orden del lenguaje.

Lenguaje que en la elaboración de Lacan constituye un gran Otro como lugar de los significantes, el Otro de la cultura, al que el sujeto no puede evitar remitirse para establecer su propio saber. Sin embargo, ningún significante puede representar el ser del sujeto ni representarse a sí mismo, en tanto la significación implica una cadena o al menos dos significantes, y sólo el sujeto puede articular al significante con el significado.

Por tanto, el sujeto no se reduce a esa cadena, tiene además un cuerpo que goza, un ser de goce que el lenguaje no logra decir y que constituye un referente real indecible. La decisión ética surge de allí como experiencia de lo femenino, como un acto no apoyado por el Otro, es, decir, al margen de cualquier orden anterior. Lo femenino en tanto instancia de donde surgen ética y sublimación renueva el orden social, resiste a la normalización, a la homogenización y constituye la alteridad, lo singular del ser, el aporte novedoso de cada uno al mundo.

\section{Palabras Claves:}

Sujeto, alteridad, acto ético, acto creativo, experiencia, goce

\section{THE FEMININE : A PO-ETHICS}

\section{Abstract}

This article seeks to explain the subject experience of feminine, as an instance of which arises both, the ethical act and the creative act. The article makes the differentiation between the individual and the significant's subject and to place the being's enjoyment otherness with regard to the language's order. 
This language in Lacan's theory constitutes a "great Other" as the place of all significants, the Other of culture, so the subject can not avoid to look it for establishing his own knowledge. However, the significant don't may represents the subject's being neither represents by himself, while the significance implies a chain or at least two significants, and only the subject can articulate the significant with the meaning.

Therefore, the subject is not limited to this chain, he also has a body that enjoys, an being's enjoyment which the language can not say and that is an ineffable real reference. The ethical decision arises from there as an experience of feminine in a subject, as an act not supported by the Other, apart from any previous order.

The feminine, as an instance from which arises ethics and sublimation, renews the social order, resists to standardization, to homogenization and constitutes the otherness, the singular being, like the new contribution of each one to the world.

\section{Key Words:}

Subject, otherness, ethical act, creative act, experience, enjoyment

\section{Introducción}

En la cotidianidad contemporánea ha aparecido cierta censura sobre el significante universal de los sustantivos humanos; significante que -en lengua castellana- es comúnmente homónimo del masculino. Quienes agencian tal prohibición, proponen suplantar al universal por la dupla de dos particulares: el sustantivo masculino y su homólogo femenino. Vetar homónimos y pretender que los universales equivalen a la suma de algunos particulares -lejos de ser una trivialidad - constituye una censura a la actividad clasificatoria primaria de la cual depende el pensamiento, además expresa la creencia errónea de que basta el significante para representar al ser, y finalmente, elude tomar en serio la discriminación ancestral contra lo femenino de cada sujeto, sin importar cuál sea su anatomía.

El tesoro de los significantes -como lo llamaba Saussure- ese gran Otro Cultural de la lengua que nos precede, soporta bien incluso neologismos, extranjerismos y toda clase de cicatrices que dejan en su sistema los hechos sociales ${ }^{3}$ y la subjetividad propia de un tiempo. Pero, eso no debe soslayar la advertencia sobre las consecuencias nefastas que ha tenido en la historia, controlar, censurar o forzar la palabra.

Cierto es que no existe 'La' fórmula del ser hombre o mujer, pero, por la misma causa, no se puede eludir el enigma que así señala un espacio ético al sujeto. La actual situación social ha inducido a varios investigadores del devenir contemporáneo, a innovar sobre la ética requerida para la convivencia, desafortunadamente, desdeñan la ética singular más que considerar el reto que plantea; de allí la pertinencia de los aportes que Lacan hizo al psicoanálisis sobre la alteridad y la ética del sujeto.

Entre esos investigadores encontramos estudiosos de la bioética como Zubiri ${ }^{4}$ o Diego Gracia, ${ }^{5}$ preocupados por los dilemas que se plantean entre la experimentación genética y la alteración de lo obtenido hasta ahora por la selección natural; educadores filósofos, como Fritz Oser y Adela Cortina, ${ }^{6}$ se afanan por alcanzar la dimensión ética con una educación moral y ciudadana que ajuste más sus didácticas al modelo 'científicocognitivo'; mientras el estructuralista Paolo Virno, analiza el auge actual de oportunismo

3. de Saussure, F. (1945) Curso de lingüística general, Buenos Aires: Editorial Losada, pp. 135 - 145.

4. Cf. Zubiri, X. (1987) Naturaleza, historia, Dios, Madrid: Alianza, pp. 322 y siguientes.

5. Cf. Gracia, D. (1996) "Ética de la sexualidad", en Ética de los confinas de la vida, Bogotá, Editorial El Buho, pp. 29 a 55.

6. Cf. Cortina, A. (1995, enero - abril) "La educación del hombre y el ciudadano", en Revista Iberoamericana de educación, pp. 41 a 63.

7. Cf. Virno, P. (2002) Gramática de la multitud, Lecciones del doctorado "Ciencia, tecnología y sociedad" en la Universidad de la Calabria, consultado [en línea] el 11 de junio de 2006 en http://ivan.domingo.googlepages.com/cuandoelverbosehacecarne3. 
y cinismo, como consecuencia del relevo de la expoliación de la fuerza física por la explotación del 'intelecto' (poder del discurso del amo y del discurso universitario).

Estos esfuerzos tienen el valor de intentar construir nuevo saber, que permita comprender el lazo social de nuestra época. El investigador italiano Paolo Virno, por ejemplo, por vía del marxismo, diferencia la expoliación del general intellect $^{8}$ de la del trabajo físico y saca interesantes consecuencias sobre los nuevos sentimientos, las posiciones morales posmodernas y las innovaciones en el tiempo del trabajo, derivados del cambio en las fuerzas productivas; sin embargo, la dimensión ética que persigue, se le escapa, en tanto se fía demasiado, no del conocimiento, sino de la comunicación.

Virno propone como alternativa emancipatoria un éxodo fuera del dominio estatal y confía ese logro a una multitud espinoziana en oposición al Leviatán de Hobbes, por ello apela a lo que llama 'la gramática de la multitud'; el problema es que desde el estudio de Freud sobre la psicología de masas, sabemos bien que esa precisamente es su gramática: el paso de las elaboraciones significantes del sujeto singular a la fascinación hipnótica de los signos que en la masa producen el contagio emotivo, luego la identificación de un objeto externo con el ideal de cada uno y con ello la masificación. La propuesta de Virno implica todavía esas redes de lenguaje; pero quizás cuando habla de éxodo tiene la aprehensión de algo emancipador fuera de sus límites. Dicho de otro modo, el problema de estas elaboraciones, es suponer que nada existe fuera de un "todo fálico". Tanto en el análisis de Virno, como en la carrera bioética donde el saber médico compite con la combinatoria genética que opera en lo real, como en la citada guerra contra los homónimos, lo que sigue excluido es la alteridad, la dimensión 'otra' de la vida humana, la inefable, es decir, la experiencia posible de lo femenino en el sujeto, cualquiera que sea su anatomía; vale insistir, la experiencia de lo femenino que puede tener un sujeto anatómicamente hombre o mujer.

Sí, para articular femenino y ética, hay que insistir en que lo femenino concierne al sujeto cualquiera que sea su anatomía, y que reconocer lo femenino en la experiencia propia es condición de todo fin de análisis, en tanto un psicoanálisis es ante todo un llamado a asumir la responsabilidad de lo real del goce propio: decidirse a la satisfacción parcial de las pulsiones forjando cultura. Lo que interesa pues, al psicoanálisis, no es ninguna normalización, sino cierta emancipación del sujeto, con la cual logre hacer más habitable para sí y para los otros los lazos sociales en que se inserta.

Entonces, ¿qué da cuenta de lo femenino en el sujeto, cualquiera que sea su anatomía? ¿Qué relaciones mantiene con la ética y la creación?

Veamos la distinción entre individuo y sujeto, para aclarar la 'alteridad': lo femenino; más adelante, intentaré ubicar sus relaciones con la ética y con la creación en el síntoma.

\section{Individuo y diferencia}

PaoloVirno llama'individuación'a un proceso en que la multitud spinoziana se erigiría como ente intermedio entre el pueblo de Hobbes y el individuo singular. Según el filósofo, la multitud alcanza la 'individuación' superando lo genérico y pre-individual, algo común a todos: la lengua misma. Esta idea de superar la red significante es interesante, pero no es claro cómo se realizaría esa operación en forma colectiva, más aún, cuando el investigador sugiere que la 'comunicación' o el 'intelecto general', conducirían a la multitud al éxodo hacia una organización no estatal. A contrapelo de esta argumentación surge la inquietud de que la 
individuación estimule otras alienaciones que atomizan ante el poder estatal. Por su parte, Agamben tiene un argumento distinto, el Estado-nación debilitado produce estados de excepción jurídica, entonces, del éxodo de refugiados hacia países industrializados empieza a constituir sujetos exiliados de la condición de 'ciudadanos.'

De otro lado, el poder del ultraliberalismo actual, prescinde del aparato estatal, detenta su hegemonía mediante entes financieros, comerciales, comunicadores, etc., que reciclan su control. El poder alienante ya no es del Estado, sino del discurso que el mismo sujeto reproduce como consumidor: primera distinción.

En segundo lugar, los individuos, es claro, tienen diferencias, cualquiera sea su especie; pero el organismo que fundamenta lo indiviso de la categoría 'individuo vivo', no explica nada del ser hablante. Uno de los dramas de la Modernidad deriva de concebir al ser hablante como individuo, como organismo: caja negra cuyo misterio supuesto a su interioridad, impulsa a la ciencia a abrirla, despedazarla, llevarla bajo el microscopio o hacerla reaccionar en los laboratorios, para dar al fin un día con el sustrato material del ser que piensa. En esta vía, asistimos una y otra vez a los anuncios de que 'se descubrió' el gen que determina el homosexualismo o la infidelidad, si no, como predice el cognocitivismo experimental del INSERM en Francia, qué niño desde la edad de 2 años, muestra signos premonitorios de su destino como delincuente adulto. ${ }^{10} \mathrm{Tal}$ poder de predicción, supone un determinismo cósmico, en el cual todo estaría ya referido a una secuencia de 'lo mismo': el automatón de una lógica ante la cual al individuo sólo le restaría adaptarse o recurrir al éxodo. La sociedad queda reducida a 'población de individuos', a entes 'estadísticos', cuya diferencia sólo cuenta como variable en la reproducción de ese 'lo mismo eterno'.

Esta concepción instrumental reduce la vida a mera supervivencia: toma al sujeto como la sumatoria de sus probabilidades de viviente, como organismo individual que se las arregla con su 'diferencia', adaptándose. La oposición individuo y poder, sea éste estatal o no, plantea como alternativas: el control o la huida para garantizar la sobrevivencia. Lo cual explica que los investigadores sociales en materia de formación moral, busquen nuevas formas de diques, normas, persuasiones para establecer un orden regulador. Pero... ¿regulador de qué?: del goce, claro, de eso real que llaman 'tendencias' y que está fuera de lenguaje. La ciencia lo postula innato, genético 0 biológico, antes de admitir que es el resto surgido por la función de la palabra: intromisión histórica y contingente del significante que modifica al organismo y hace surgir allí un sujeto. Desconociéndolo, la ciencia decide que la razón puede eliminar lo real del individuo orgánico, pero lo simbólico no recubre lo real, la razón tiene límites, y al insistir, la ciencia genera nuevos efectos reales, nuevo goce no simbolizado, cuyas consecuencias suelen ser devastadoras.

\section{La alteridad: lo femenino}

Al Otro -que preexiste al sujeto, que acoge al organismo aún no marcado y luego lo modifica- le suponemos un sujeto, aunque ese Otro no es más que lenguaje ${ }^{11}$, esto introduce la alteridad desde el inicio. La experiencia de palabra porta un efecto de "desnaturalización", de extrañamiento que interroga al sujeto por su ser (que no está en lo orgánico), e impone al Otro como el lugar donde tendrá que ir a buscar respuesta. El problema es que lo real también existe en el corazón del significante, en tanto cada significante aislado no significa 
nada, es asemántico y ni siquiera puede representarse a sí mismo. El Otro, como lugar de la simbólica, marca al sujeto, se introduce por el habla y deja huellas acústicas, pero hombre, mujer, judío, negro o musulmán, son sólo significantes, del ser mujer o judío, no sabe nada: ¿Qué es niña, con a? ¿Qué es hombre? Avancemos articulando otros significantes, por ejemplo: " $\mathrm{iEse}$ hombre es un hombre!", aquí la articulación sí produce efectos de significación, pero entonces descubrimos la no-identidad entre el primer S1: hombre, cuya significación difiere de la de su homónimo S2. Debido a la falta de significado del significante $\mathrm{S} 1$, sólo su articulación con un S2 induce posibles efectos de significación. Esto muestra que el significante no puede representarse solo, que los homónimos no significan lo mismo y que la significación depende del articulador (sujeto), articulador que no está incluido en el lenguaje y que supone un referente real indecible ${ }^{12}$. Ese referente real habita el sujeto, es del orden del ser.

La alteridad comienza pues, con S1, el cual, de no poder representarse a sí mismo, representa al sujeto (articulador) para S2: el saber. Determinada así por lo real, tampoco la significación surgida en la articulación con S2 restituye el saber sobre su ser al sujeto, por tanto, ese saber faltante sobre el ser es la ineliminable consecuencia de la ley significante. La sustancia de este ser que no dice su nombre es el goce, un ser negativo que resiste al sentido, Lacan lo denominó objeto a, y llamó 'falo' al significante vacío que agrupa el conjunto de los significantes que representan a un sujeto, cuya función: llamada 'función fálica' atañe tanto a los sujetos masculinos como a los femeninos, en calidad de seres hablantes y designa su sumisión a la ley significante, que Freud llamó 'castración', término que señala la 'pérdida-en-ser' ya descrita y que se produce al hablar. De esa pérdida de significación al hablar queda un residuo: el objeto a, gracias a él, los sujetos enfrentan lo imposible a decir y esa presencia que los significantes no logran representar los impulsa a continuar hablando. ¿No es evidente allí, que ese residuo real propicia el lazo social?

La pérdida de significado -pérdida en lo imaginario- evidencia el fracaso significante, que tampoco atrapa lo real, por eso las sanciones mujer $\mathrm{u}$ hombre dadas al nacimiento, no determinan un ser específico al sujeto, el goce de cada uno es inédito, único, singular; sin embargo, las mismas razones, hacen imposible fijar el significante, capaz de sancionar de una vez por todas al ser y/o al saber sobre la diferencia entre los sexos. El Otro no es un sujeto, es sólo el lugar de los significantes, por eso no sabe nada; no obstante, el sujeto tiene que remitirse a él, a sus significantes para establecer cualquier saber.

\section{El sujeto singular y social}

Cuando Lacan señala que "el inconsciente es aquella parte del discurso concreto en cuanto trans-individual que falta a la disposición del sujeto para restablecer la continuidad de su discurso conciente", ubica al inconsciente como lo social mismo. El lazo social se produce como articulación de los significantes que representan a los sujetos en torno al defecto de ser que cada uno experimenta frente al significante, alrededor del mismo tratamiento del goce por lo simbólico. Lo cual difiere de estar reunidos en torno a la falta del mismo ser. No hay ser común. Los sujetos no se unen por lo que tienen en común, sino por la falta de saber que concierne a cada uno según su historia. Lo simbólico tiene así la función de regular goces diversos, pero los sujetos y sus cuerpos, se ligan en torno a la falta de saber, 
a lo real que resta, goce articulado como inconsciente en la operación significante. Por tanto, el lazo social es irreductible a los discursos mismos. ${ }^{14}$

Dada esta dinámica del inconsciente, el sujeto es a la vez singular y social, si bien su goce, su ser de goce, es singular y determinado en su experiencia, no como construcción cultural. Así, el acierto de la histérica es denunciar que el Otro (A) es impotente para decir su ser, que ningún saber podría decirlo; su problema es reclamar por la falta-en-ser que deriva de su condición de hablante, eso la fija al falo y la separa de una relación con el Significante que falta al Otro S(A [tachado]). Pero, los avatares de la posición femenina son otro asunto; lo femenino es apertura de la alteridad hacia el síntoma y desde allí tiene implicaciones sociales: comporta la dimensión ética.

\section{La dimensión ética}

Los esfuerzos de educadores y filósofos para enseñar normas morales, revelan no sólo una confusión entre educación y ética, sino que promueven un bio-utilitarismo. Adela Cortina adopta ideales médicos, como la "auto-posesión de cuerpo y mente" y el "autocontrol" como "signos de salud", mientras considera que las elecciones morales"sólo pueden interesar a una persona -niño o adulto- si la convencemos mediante alguna gratificación o alguna sanción externa". ${ }^{15}$ En su balance, dentro de su propia comunidad los niños ganan la pertenencia que les convence. ${ }^{16}$ Evidentemente, la lógica del cambista es propia del ser hablante, determinada porlacombinatoria significante, pero la ética excede la negociación, rebasa los límites simbólicos. La educación también puede y debe transmitir la existencia de lo innegociable, lo que no tiene precio, del don a pérdida. Lo cotidiano está minado de opciones que lo reclaman. De modo que la lógica del beneficio no puede transmitir más que elecciones de orden instrumental y utilitario.

La ética comporta una dimensión inscrita por la elección insondable del ser del sujeto, allí donde ya no puede contar con el Otro, dimensión al margen de las leyes sociales, de las normas morales de convivencia o los códigos legales.

La ética comporta la dimensión del acto sin Otro. De ello da cuenta Agamben en su texto Sin rango, cuando cita a Pico de la Mirandola, quien dijo en De hominis dignitate: "que el hombre, al haber sido plasmado cuando se habían agotado los modelos de la creación, no puede tener ni arquetipo ni lugar propio ni rango específico". ${ }^{17}$

Entonces, si lo que define al hombre no es una sustancia positiva, por no tener rango -en nuestros términos: por el fracaso significante para dar cuenta de su ser- por su ausencia de dignitas, el ser hablante está conminado a elegir una, a constituirla con sus actos. Sólo el ser hablante enfrenta la dimensión del acto, sólo por su precaria libertad, el ser hablante se determina en el 'siendo' continuo que es lo inconsciente. Para apuntalar la reflexión sobre la ética de Agamben, cito este otro texto:

El hecho del que debe partir todo discurso sobre la ética es que el hombre no es, ni ha de ser o realizar ninguna esencia, ninguna vocación histórica o espiritual, ningún destino biológico. Sólo por esto puede existir algo así como una ética: pues está claro que si el hombre fuese o tuviese que ser esta o aquella sustancia, este o aquel destino, no existiría experiencia ética posible, y sólo habría tareas que realizar. Esto no significa, todavía, que el hombre

14.Para mayor amplitud de la elaboración sobre el fracaso significante y la renovación del lazo social por lo femenino, recomiendo consultar el texto Le feminin et le lien social, de Marie-Jean Sauret, circulado en el correo de la Association Psychanalytique Jacques Lacan:apjl@wanadoo.fr.

15. Cf. A. Cortina. (1995, enero - abril) "La educación del hombre y el ciudadano", en Revista lberoamericana de educación, pp. 50 y 52.

16. Cf. Op. Cit. p. 53. [El subrayado es mío]

17.Agamben, G. (2005) “Sin rango", Lo abierto, El hombre y el animal, Valencia, Pre-textos, p. 43. 
no sea ni tenga que ser alguna cosa, que esté simplemente consignado a la nada y por tanto pueda decidir a su arbitrio ser o no ser, asignarse o no este o aquel destino (nihilismo y decisionismo se encuentran en este punto). Hay, de hecho, alguna cosa que el hombre es y tiene que pensar, pero esto no es una esencia, ni es tampoco propiamente, una cosa: es el simple hecho de la propia existencia como posibilidad y potencia. Pero justo por esto todo se complica, justo por esto la ética llega a ser efectiva. ${ }^{18}$

El filósofo señala bien la 'elección forzada' del sujeto como opción de ser, tomada a partir del Otro y sus significantes, ser que no existe entonces por obra del libre arbitrio, pero tampoco se reduce a la nada. Agamben señala al ser como un hecho, aunque desconocido, cuando dice "el hombre tiene que pensar" en esa 'alguna cosa que él es'. Así, la "propia existencia como posibilidad y potencia" no está determinada ni dicha, pero es ya de algún modo, que, avancemos: está en un más allá de la función fálica, más allá del significante recibido del Otro. En términos analíticos: la ética apunta al ser cuyo significante falta en el Otro S(A [tachado]).

Ahora bien, la palabra hace acto y todo acto verdadero es al mismo tiempo un acto ético, como el que permite a un analizante salir de su alienación al Otro, dejar de impugnarle los defectos del goce y reclamarle por su faltaen-ser. Precisamente, del fin de un análisis se espera que el sujeto renuncie a rehabilitar al Otro y acepte la irreductible alteridad surgida por el hecho de hablar; admita que si bien no es posible decir el ser, hay un resto, un goce singular irrenunciable, con el cual debe contarse.

Cuando Agamben dice: "Hay, de hecho, alguna cosa que el hombre es y tiene que pensar", no creo que ese 'pensar' sea el conocimiento, debe más bien parecerse al trabajo del poeta o del analizante, conminado a afrontar la alteridad de su palabra, los límites del desciframiento y los límites de la función fálica, donde el ser negativo está siendo, y sólo se revela en acto. Ese 'pensar' no produce conocimiento sino la decisión de aceptar la falta en el Otro, de 'desfalizarse', esto es, pasar de la queja por impotencia a admitir que existe lo imposible, entonces, a partir de allí, se podrá recrear otra manera de arreglárselas con el síntoma, es decir, inventar cómo vivir lo posible.

\section{Lo femenino: posibilidad estética y ética}

El efecto emancipador del psicoanálisis no es la erradicación del goce singular, sino la desactivación del goce mortífero; así, el goce se revelará parcial y defectuoso pero posible: el objeto a es irreductible. El sujeto necesita asegurar que su singularidad no será reducida ni a lo simbólico ni a lo imaginario. La formación de compromiso que le da esa seguridad es el síntoma. Entonces, la novedad en un análisis aparece cuando el objeto a anuda lo real con el lenguaje y el cuerpo. Lacan veía una afinidad entre lo femenino y la creación, el anudamiento exige creación, un acto que invente un nuevo soporte del ser singular.

Así, el síntoma permite al sujeto que aquello que lo distanciaba de otros, pueda devenir el motivo que le haga un lugar entre ellos. El trabajo analítico pretende que el sujeto no tenga que renunciar a su singularidad y aprenda a arreglárselas con ella. Pero el sujeto que asume su alteridad debe afrontar la soledad que implica dirigirse a S(A [tachado]); esto lo aísla de otros, cualquiera que sea su anatomía.

Marie-Jean Sauret describe qué se espera como renovación del lazo social por lo femenino:

un lazo social donde el sujeto testimoniaría de una"nueva bisexualidad": tal que, si adopta la posición "masculina" sabría que sostiene su singularidad de lo femenino que 
él habita, y tal que, si adopta la posición "femenina", sabrá que gracias a lo masculino que lo anima escapa al matrimonio siempre religioso con el Ser sin existencia. ${ }^{19}$ De una u otra forma, habrá de consentir a lo femenino que le "suplementa", como acoger lo femenino que le solicita, para reinventar el mundo... ${ }^{20}$

\section{El hombre y lo femenino}

Isabel Morin dijo en un seminario: "El decir femenino es un decir de poeta. Cuando un hombre es poeta significa que se aproxima a lo femenino, esta experiencia lo exilia, en parte, de la comunidad de los hombres". ${ }^{21}$ Acojo esta observación para presentar apartes de la literatura de Imre Kertész, pero no precisamente Sin destino, la novela por la cual la Academia de Estocolmo juzgó que merecía el Premio Nobel en 2002, sino Kaddish por el hijo no nacido, escrito de tono testimonial, en primera persona, que aunque designa un amor, no lo cuenta, no tiene el menor interés de entretener o seducir al lector con el suspenso de una trama, ni recrea una historia. Su itinerario es más bien hilado del sujeto, que se repliega en apartes de la cadena significante, de la cual recoge esquirlas sin tiempo. Por eso, sus 'antes' y 'después' no se ocupan de la cronología, sino de un devenir que elabora a posteriori, en un presente nuevo.

A diferencia de Sin destino, la prosa del Kaddish es poética, su urdimbre está a cargo de la contundencia sonora y de un ritmado golpe de palabras, donde las frases vuelven sobre sí mismas, se enfatizan con repeticiones, se interrumpen con objeciones y luego continúan en una ruta de argumentación sin cuidado por la contradicción, a la que más bien convoca. El protagonista dice sufrir ataques verborréicos $y$ el escritor funge como escriba del texto completo dictado de un solo golpe y tejido como telaraña polifónica en torno al significante: $<<$ iNo! $>>$. De allí que el texto no tenga capítulos ni cortes que permitan al lector darse una pausa, el sin-tiempo lo induce a proseguir, si acepta rendirle su escucha, o a detenerse para recapitular y establecer mojones en el espacio de esa otra temporalidad del protagonista.

Una infancia, una experiencia en los campos de concentración, una creencia arcaica, retornos, el encuentro de una mujer, secuelas y la escritura como cicatriz del trauma, surgen como se exponen sobre la mesa de juego las cartas de una baraja. Ciertas secuencias se hacen y deshacen, avanzando argumentos que generan su propia destitución, creando un amplio entramado vital que atraviesa diques al sentido. El texto no es mera denuncia ni advertencia, ni relato socio-histórico de Auschwitz, pero el Lager tiene un lugar central como tiempo lógico, como experiencia de un duro proceso de comprensión. Lo que en ocasiones parecería un monólogo, deja de serlo cuando se dirige al niño jamás concebido: destino y causa supuesta de la plegaria.

\section{La oración}

El kaddish es una oración fúnebre judía dicen los entendidos-, en la cual "se acepta tácitamente que el veredicto promulgado para el fallecimiento del ser querido debe tener alguna razón, quizás inaccesible para el entendimiento de los que le sobreviven, pero que seguramente entra dentro de los planes de Hashem".22 Dentro del marco de la tradición judía, el kaddish es pues una aceptación de los límites de la vida, dirigida a Dios, dirigida al Otro para aceptar su voluntad y parte del trabajo de duelo, que encuentra consuelo a la pérdida en la fe que instituye al Otro.

19. - On ne naît pas femme, destinée toujours singulière; sur les "religieuses", voir Michel Deguy, op. cit. p. 35. [Traducción no revisada: No se nace mujer, destino siempre singular; sobre las "religiosas", ver Michel Deguy, op.cit. p. 35. La cita del autor está bajo el epígrafe del texto que dice: "Heterósido. Cada uno mata lo que ama". M. Deguy. Homme de peu de foi, París, Bayard, 2002, p. 15.]

20. Sauret, M. J. (abril 24 de 2004) Le feminin et le lien social, Texto distribuido por el correo electrónico de la Association Psychanalitique Jacques Lacan APJL, Toulouse, Nantes. [Traducción mía, no revisada por el autor].

21. Morin, I. (2003) "Lo femenino y la insurrección", en El enigma de lo femenino y el goce, Medellín, Asociación de foros del campo lacaniano de Medellín, p. 108.

22. Lic. Yehuda Ribco. El Kaddish y la Muerte, recuperado el 5 de junio de 2006, en http://www.geocities.com/yargg/kaddishymuerte.htm 
La novela de Kertész muestra secuelas de un duelo, de una pérdida radical, de una muerte, cuya pena nombra con ese significante de la tradición judía. Situada en la tradición, sería una sumisión al Otro, sin embargo, el texto no está dirigido a Dios sino al niño, es una rendición de cuentas o explicaciones que se le dan a un niño, precisamente a ese que jamás nació, al que jamás fue concebido. Por eso no es una rogativa, no hay un pedido de clemencia, menos aun expiación. El conjunto de los significantes del texto se ordena en relación con el significante inicial, que se reitera en fragmentos ulteriores: $<<<_{i}$ No! $>>$, escrito así, siempre con mayúsculas, admiración y comillas, proferido como respuesta a la insinuación sobre la posibilidad de que ese niño, el hijo posible, viniera alguna vez al mundo.

Con esa negación reiterada, recuerdo que Isabel Morin dice: "la insurrección femenina podría ser silenciosa. [...] es una insumisión fundamental a los valores masculinos del poder, de la posesión y de la muerte. Es un decir "que no"z3 al cual puede faltar el decir no." Volveremos sobre este punto.

\section{¿Qué es 'judío'?}

La condición de 'judío' interroga al protagonista durante la infancia, cuando se ubicaba entre los suyos en calidad de 'nojudío', ya que sus padres no practicaban la tradición; su primera relación con ella surge como un mal encuentro, durante una visita a la casa de sus tíos. Aquí, la descripción del encuentro traumático:

una mañana abrí, imprudente yo, la puerta del dormitorio y enseguida me marché soltando un grito, no en voz alta, claro está, sino sólo en mi interior, porque había visto algo horripilante, algo que me pareció una obscenidad, algo para lo cual, debido a mi edad, no podía estar preparado: una mujer calva estaba sentada delante del espejo, con una bata colorada. ${ }^{24}$

De aquella primera aparición dice haber sido: "la primera metamorfosis importante y llamativa de mi vida",25 luego, al pedir una explicación al padre, éste se ríe:

la risa no recogía en absoluto ese espanto y en cambio le añadía otros, con suma amabilidad, eso sí, al explicar mi padre, de manera del todo ininteligible para mí, de suerte que sólo comprendí el espanto puro de los hechos 0 , para ser más preciso, su facticidad simple, misteriosa e insondable, al explicar digo, que mi tía y mis parientes eran polisch y que las mujeres polisch se rapaban por motivos religiosos y llevaban una peluca llamada schatli; más tarde, cuando mi condición de judío empezó a resultar cada vez más relevante, por cuanto tal condición implicaba en general la sentencia de muerte, como fue demostrándose con el paso del tiempo, de pronto tomé conciencia de que ya sabía quién era, probablemente por el simple afán de ver esa circunstancia especial -0 sea, el hecho de ser judío - en toda su singularidad, pero también, al menos, bajo una luz familiar: yo era una mujer calva sentada delante del espejo, con una bata colorada. ${ }^{26}$

Luego, el protagonista dice no haber necesitado recurrir a esa definición por haber hecho las paces con la idea de ser judío, de la misma manera que lo hacía con otras ideas desagradables, incluso, debido a su peligrosidad, resuelve que "debe intentar querer encontrar la utilidad de lo incomprensible".27 En una ocasión espía la conversación de dos mujeres, sentadas en la mesa contigua en un café, escucha entonces, que una de ellas dice:

no sé, yo no podría con un extraño... con un negro, un gitano, un árabe..."[...] ". . o con un judío", y fue en ese momento cuando de pronto, de manera del todo inesperada aunque, de hecho, contaba con esa apostilla, la esperaba, la exigía por así decirlo, de pronto, repito, 
el mundo dio una vuelta conmigo alrededor de su eje, provocándome un vértigo repentino que me estrechó el estómago y me dio la sensación de estar cayendo y entonces pensé que si esa mujer me miraba, yo me transformaría: en una mujer calva sentada ante el espejo, con una bata colorada... ${ }^{28}$

El significante 'judío' remite al protagonista a la articulación de esos S2 (en cursivas): significación insoportable que hace conjunto con los significantes que pronunció su padre: polisch, schatli. Pero en cierto modo el significante 'judío' sigue inasumible, por la presencia de lo real, de la alteridad, más inquietante en tanto se concreta en la imagen de la mujer calva (la calvicie es más usual en el hombre). La incomprensible alteridad aparece como un extraño femenino.

\section{El acto de crear otra vida: ética y lazo social}

La experiencia en el Lager enfatiza la alteridad surgida del significante 'judío' y la escritura da cuenta de "una suerte de ataque de verborrea". Cuando en medio de un grupo de judíos, un hombre dice que $<<$ Auschwitz no tiene explicación>, el "ataque" sobreviene y su contra-argumentación sólo toma respiro ¡10 páginas después!, para dar paso al episodio en el que reconocerá la dimensión ética:

así que para que os hagáis una idea cabal de la situación bastará con que os diga Lager, invierno, traslado de enfermos, vagones de transporte de ganado, una sola ración de comida fría aunque quién sabe cuántos días durará el viaje, reparto de las raciones en unidades de diez, y yo que, tumbado en un armazón de madera llamado camilla, no pierdo de vista, con mis ojos de perro, a la persona a la que fue a parar mi ración, un hombre, 0 mejor dicho, un esqueleto denominado, no sé por qué, "señor maestro", y entrada en los vagones y las cuentas que no cuadran una y otra vez, y gritos y confusión y una patada, y yo que entonces siento que me cogen y me plantan delante del siguiente vagón y que he dejado de ver al "señor maestro"y mi ración. ¿Y qué sentí? En primer lugar no podía dar de comer a mi eterno torturador, al hambre, a esa fiera furiosa, exigente y hace tiempo ajena a mí, y luego empezó a bramar la otra fiera, la esperanza, que hasta entonces sólo había ronroneado, con voz sorda y apagada, insinuando que a pesar de todo siempre quedaba alguna posibilidad de supervivencia. Sin embargo, ésta resultaba en aquel momento sumamente dudosa debido a la desaparición de mi ración, la cual, por otra parte, duplicaba exactamente las posibilidades de sobrevivir del "señor maestro"; así se acabó mi ración, pensé sin mucha alegría, para qué negarlo, pero de manera racional en sumo grado. ¿Pero qué veo al cabo de unos minutos? Al "señor maestro" que se me acerca, gritando y buscando con mirada angustiada, con mi ración fría en la mano, y cuando me ve en la camilla, me la pone con un gesto rápido sobre la barriga. Quiero decir algo, y tengo por lo visto el asombro dibujado en la cara, porque él, si bien vuelve corriendo a su sitio -pues de lo contrario lo zurrarían a muerte- porque él, digo, pregunta con indignación claramente perceptible en ese rostro pequeño y ya preparado para la muerte: "¿Tú qué te creías...? ${ }^{29}$

¿Cuál es la lógica de lo que hizo el "señor maestro"? Su situación recuerda el espacio 'entre dos muertes' donde Lacan situó la ley ex-nihilo que guió a Antígona, ${ }^{30}$ así lo entiende el protagonista:

el "señor maestro" hizo lo que hizo para que yo sobreviviera, desde mi perspectiva, claro está, pues a él lo guiaba otra cosa, como es lógico, él actuó por su propia supervivencia y de paso también por la mía. Y he aquí la pregunta: explicadme si podéis por qué lo hizo. Pero no intentéis con palabras, pues sabéis también que en ciertas circunstancias, las palabras pierden su sustancia, su significado, se destruyen, de tal modo que en ese estado gaseoso, sólo los hechos, los meros hechos presentan cierta tendencia a la solidez, se pueden poner sobre la mano y sopesarse como un mineral mudo, un cristal. $^{31}$

"Un acto ético -explica Slavoj Zizek- no está sólo "más allá del principio de realidad"; sino que designa, antes bien, una intervención 
que cambia las propias coordenadas del "principio de realidad." [...] un acto no es sólo un gesto que "hace lo imposible", sino una intervención en la realidad social que cambia las propias coordenadas de lo que se percibe como "posible"; no está meramente "por encima del bien": cambia la definición de lo que se tiene por "bien".32

El pasaje siguiente muestra que este acto, este afuera de lenguaje, da un rango al "señor maestro" y es creación de un nuevo bien, 'otra-forma-de-vida' que la del Lager y precisamente en su seno: el "señor maestro" crea y elige -sobreviva o no-, darse otro rango que aquel de 'mero sobreviviente'.

la aceptación de esta segunda posibilidad habría supuesto para él, por así decirlo, la destrucción de la única posibilidad que le permitiría vivir y sobrevivir; por tanto hay algo -y una vez más os pido que no lo intentéis con palabras-, existe un concepto puro, no contaminado por ninguna materia: ni por nuestro cuerpo, ni por nuestra alma, ni por nuestras fieras, una noción que vive como una representación idéntica en la mente de todos nosotros, sí una idea, cuya inviolabilidad 0 custodia 0 como queráis Ilamarlo es la única verdadera posibilidad de supervivencia. ${ }^{33}$

Su testimonio de que "hay", de que "existe" algo "no contaminado" en todos nosotros, es la evidencia de su viraje ante lo real ligado al significante 'judío', y esto, como efecto creador del acto: Eso fuera del lenguaje proveniente de otro 'judío', creó un lazo. Como dijimos antes, los sujetos no se ligan por los discursos, sino por la falta-en-ser que les convoca en el mismo tratamiento significante.

\section{La pérdida que justifica el kaddish}

que hizo su esposa, esa presencia viene intermitentemente, también la del niño, en estribillos cargados de emoción:"Luego llegó mi mujer, y yo, pensé en el acto, y de manera, por decirlo así, instintiva: <<¡Qué judía más bella!>> cuando atravesó la alfombra de color azul verdoso como si fuese el mar ${ }^{134} \mathrm{Su}$ experiencia con ella aparece fragmentada y dispersa a lo largo del escrito, pero aquí la inserta a continuación de otro estribillo dirigido al niño:

Sí, así fue, y ahora veo toda nuestra vida, todos sus tonos, sucesos y sentimientos como una unidad borrosa y confusa 0 , por extraño que parezca, la oigo más bien, como un entramado musical donde el tema principal, grande único y arrasador, va madurando y espesándose hasta estallar y asumir, autocrático, el poder en solitario, acallando todo lo demás: mi existencia vista como posibilidad de tu ser, y luego: tu no-existencia vista como liquidación necesaria y radical de mi existencia. ${ }^{35}$

Esta "liquidación necesaria y radical" de su existencia, no es suicidio, ni renuncia a elaborar la vida, es más bien un 'decir no' a la paternidad. Un hombre -uno que dice sí a la función fálica, lo que quiere decir estar todo sometido a la ley significante y que llamamos un 'castrado'-, cuando deviene padre se convierte en excepción, en el único 'no castrado' para el niño; el protagonista de la novela renuncia a esta posibilidad. ¿Por qué? Aquí tropezamos con la reticencia del escrito a dejarse citar, lo que Lacan escribiría reti-sens ${ }^{36}$. Los lugares en los cuales se apunta la significación están dispersos, adelante y atrás en el texto; las comas y los dos puntos ortográficos pululan, pero no hay puntos simples que permitan hacer cortes, cada cita podría ocupar dos, tres, cuatro páginas, so pena de quedar sin sentido. Pero, lo cito para mostrar la calidad del hilado y la emoción en sus intersticios.

32. Zizek, S. (2002) "El acto ético, más allá del principio de realidad", en ¿Quién dijo totalitarismo?, Pre-textos, Valencia, p. 193. [Las comillas y las cursivas son del autor, el subrayado es mío]

33. Kertész, I. Op. Cit.pp. 56 y 57. [Las cursivas pertenecen al texto de autor y señalan la existencia de una dimensión fuera del campo de las palabras, fuera del Otro $(A)]$.

34. Kertész, I. Op. Cit. pp. 27, 28, 35.

35. lbíd. p. 88.

36. Equívoco homofónico en francés, entre 'reticencia'y 'reti-sentido'. 
Esta dificultad afirma la irrupción de algo que atraviesa al poeta, lo embarga y que se localiza del lado real que resta del significante. A diferencia de su novela Sin destino, este escrito, más que narrar, pulsa, y en esa palpitación está la vida, pedazos de historia en apartes, pero más que ella está su música, vibrando palabras que no acaban de significar, no obstante, diciendo.

Aunque con excesivos recortes y corchetes, veamos cómo sitúa la relación con el hijo no nacido:

tal como nací, pues, soy cómplice de mi supervivencia igual que de mi nacimiento, bueno, admito que mi supervivencia tal vez implica un poquito más de infamia, sobre todo habiendo hecho cuanto estaba en nuestras manos para sobrevivir: [...] sobreviví, luego existo, pensé, no, no pensé nada, sólo existía, sin más, cual superviviente que no le da más vueltas a su supervivencia [...] aunque sólo sea el triunfo más silencioso, más discreto e íntimo, el único esencialmente verdadero, el único posible que sería -habría sido- prolongar y multiplicar la supervivencia, prolongar esta existencia sobreviviente, o sea, a mí mismo, en los descendientes en el descendiente-, en ti, no, no pensé en ello, no pensé que debía pensar en ello, hasta que se me vino encima esa noche, esa noche resplandeciente $y$, sin embargo, oscura, como boca de lobo, y se alzó en mi la pregunta [...] la pregunta sí, si serías una niña de ojos negros y de pequitas pálidas esparcidas alrededor de la nariz 0 un niño travieso de ojos de color azul grisáceo, alegres y duros como guijarros, sí, mi existencia vista como posibilidad de tu ser, vista, sí, contemplada con rigor, con tristeza, sin rabia, ni esperanza, cual se contempla un objeto. ${ }^{37}$

La imagen del hijo hipotético-que reaparece en varios fragmentos-, revela la pérdida que justifica el kaddish. Pero no está aún listo a proferir su $<<$ iNo! $>>$ : esta reflexión está en un tiempo anterior, cuando surgió la pregunta. Luego dice "el matrimonio empezó a manifestarse tal como era: como una contradicción" ${ }^{\prime \prime 3}{ }^{8} Y$ más adelante:

Por aquellas fechas me ocupaba de una idea [...] el proyecto de una obra literaria extensa, cuyo contenido, sin parar ahora en detalles era el camino de un alma [...] la felicidad vista como obligación". [...] por así decirlo, juntos criamos aquel proyecto, juntos lo mimamos y lo acariciamos como si se tratase de nuestro hijo. Visto a posteriori, fue sin duda un error, claro está, fue una equivocación introducir a mi mujer en este territorio, el más sensible, el más concreto, el más desprotegido de mi vida, de mi existencia, en ese terreno que es, en una palabra, mi trabajo, [...] por otra parte no estaba dispuesto a prescindir de él. ${ }^{39}$

La esposa le instará a no ser "apocado" a tener "éxito como escritor", tal como ella afirma "es lo que quieren todos", él no le replica, pero se pregunta: "¿Cómo explicarle que ni podía concluir mi autoliquidación, mi única misión en la tierra, mientras abrigara en mi interior falsas segundas intenciones, tales como resultado, literatura, e incluso éxito?".40 Después, ella le confesará que lo que quiere es un hijo y es entonces cuando descarga una secuencia de ese $\langle<$ iNo! $>>$, del que aclara:

sin embargo, dije, no digo un no-al-judío, no lo digo a despecho de todo, porque no existe nada más espantoso, nada más infame, destructivo y autonegador que este no racional, por así decirlo, este no-al-judío, no hay nada más barato ni nada más cobarde, dije, y estoy harto de que los asesinos y negadores de la vida proclamen a voz en cuello ser ellos la vida, porque ocurre con demasiada frecuencia, dije, para que despierte en mí ni que sea el discurso de la contradicción, no hay nada más terrible, nada más infame que negar la vida por complacer a los negadores de la vida, pues hasta en Auschwitz nacieron niños, dije, y a mi mujer, claro, le gustó este argumento, aunque creo difícil que me entendiera porque probablemente ni yo mismo me entendía. ${ }^{41}$

Cuatro páginas más adelante del mismo argumento, afirma: " $<<$ ¡No! $>>$ nunca podré ser padre, destino, dios, de otra persona."

37. Kertész, I. Op Cit.pp. 38 - 39.

38. Ibíd.p. 102

39. Ibíd. p. 103.

40. Ibíd. p. 105

41. Ibíd.pp. $109-110$. 
Acto seguido, lee unas notas en papelitos que escribe y guarda en su escritorio:

Entregarse a la infancia como a la muerte, leo. Ya en mi infancia pensaba a menudo, leo, que el poder significa en todo caso régimen de terror, y leo también mi propio comentario a este (de Thomas Bernhard): $<<$ yel régimen de terror significa en todo caso poder paterno $>>.^{42}$

Pero, si la decisión de renunciara la paternidad fue asumida y manifiesta, ¿cuál es la pérdida que justifica el duelo? Confiesa en un escrito destinado a su mujer: "volverá a ocurrir que estiraré mi mano hacia ti y desearé, desearé única y exclusivamente, que seas mía, o sea, cuando tú también estires la mano y ya seas por fin mía, frenaré tu entrega para preservar aquello que considero mi libertad...."43

Deseaba a su mujer, sin embargo, luego de negarle el hijo no podrá evitar perderla. Ella le anuncia que ha conocido a 'alguien' con quien ha decidido casarse:"Y que él, añadió, no era judío". Sólo entonces lo hiere, en ese punto preciso. La ofensa inicia un ataque verborréico, que esta vez porta el carácter de una conclusión y de una elección. En medio de gritos aclara a su mujer, que no le preocupa la integración de razas, sino que lo que está en juego es integrarse o no a la época: adaptarse; que el problema es decidir si se cede o no a la "integración total en las circunstancias existentes y en las condiciones establecidas". Reconoce que desde la infancia percibió con claridad que no se integraría en lo establecido, pues antes de hacerlo, la integración le mataría. Esta es su real insurrección, su 'decir no', que le permite asumir su condición de 'judío'. Cito el fragmento:

En este sentido, me importa un rábano si soy judío o no soy judío, aunque en este caso el ser judío es sin duda una gran ventaja, y sólo - ¿me entiendes?, grité-, sólo y exclusivamente desde esta única perspectiva estaba yo dispuesto a ser judío, sólo desde este punto de vista consideraba una fortuna e incluso una fortuna extraordinaria y hasta una merced no el ser judío, porque me importaba un pepino lo que era, grité, sino el hecho de haber estado en Auschwitz como un judío estigmatizado y de haber vivido algo por ser judío, de haberle visto la cara, de saber, para siempre y de manera imborrable, algo que no suelto, que no soltaré jamás, grité. Callé en el acto. Luego nos divorciamos. ${ }^{44}$

\section{Lo femenino y la política contemporánea}

Antes de continuar con la experiencia poética, detengámonos en esa estigmatización que surge de adjudicar el ser al significante (fijar el ser como 'diferencia') y negar la alteridad: Agamben plantea la crisis de los Estadosnación y la alteración en su orden jurídico que producen los exiliados: "el refugiado -esta figura aparentemente marginalmerece ser considerado la figura central de nuestra historia política".45 Es decir que -en lo que concierne al orden político-social-, la creciente "masa residente estable de nociudadanos" de los Estados industrializados, prueba el fracaso del significante 'ciudadano', el cual ya no significa nada: entonces, lo que está en juego es la vida, ese afuera de discurso, que en el hombre no es mera biología, sino su ser. La estigmatización es un intento de fijar ese ser por el lenguaje, pero para el sujeto sólo logra subrayar el exilio de su ser respecto al significante, de allí que lo fuerce a comprender. La experiencia del 'judío' en el Lager constituye un paradigma contemporáneo del desconocimiento de la alteridad y sus consecuencias en el lazo social.

La obra de Kertész es vigente para judíos y no-judíos, pues ni siquiera decirse 'ciudadano' remedia que sea preciso reconocer la alteridad, para que sobreviva la singularidad, ya no en el Lager, sino ahora y en los lugares que supone la recomposición política en curso, tal como advierte Agamben en su texto: 
La supervivencia política de los hombres sólo es pensable hoy en una tierra donde los espacios de los Estados hayan sido perforados y topológicamente deformados de aquella manera ${ }^{46}$ y en que el ciudadano haya sabido reconocer al refugiado que él mismo es. ${ }^{47}$

La reacción contra la alteridad del 'judío' hizo dramática su experiencia del Lager, pero eso mismo fue una 'ventaja'. Comprendido así lo que no habría sido tan evidente de otro modo, importa poco el significante 'judío', que siempre fracasa en decir el ser; pero fue preciso "haberle visto la cara" para reconocer su imposible y admitir lo real de la singularidad, a la cual, el judío de la novela, ya no quiere renunciar, menos aún en calidad de 'escritor de éxito' en torno a lo cual el exilio es el mismo y la negación de la alteridad se reitera como, lo que Kertész Ilama: 'integración total'. El momento de esa afirmación coincide con el de la pérdida del objeto de deseo y de amor, que motiva el kaddish. La oración está dirigida al lugar mismo de la pérdida asumida: al hijo que negó al precio de perder a su mujer.

\section{La experiencia poética}

Asumir la alteridad no ahorra la soledad al sujeto, sin embargo, hay algo a lo cual puede dirigirse aún, el poeta es aquel que temporalmente se dirige al lugar donde el significante falta al Otro, es pues, más allá del Otro, en ese espacio, que el protagonista llama de libertad, donde logra crear. Este es un lugar vital y privilegiado, que lo separa de otros, que lo aísla y manifiesta lo femenino en un hombre que, por lo demás, conserva su posición masculina.

Demos ahora la palabra al escritor para que sea su voz la que testimonie su experiencia:

Sí, porque, según parece, topo con energías creadoras en el dolor, y da igual a qué precio, y me es del todo indiferente si en la energía creadora se plasma simplemente la vulgar compensación, el hecho es que se plasma y que gracias al dolor vivo en una suerte de verdad y que si no viviera en ella, la verdad, quién sabe, me dejaría frío: así, sin embargo, la imagen del dolor se entrelaza dentro de mí, de forma íntima y permanente, con el rostro de la vida, con el rostro - de eso estoy seguro - más real de la vida. ${ }^{48}$

\section{Lo femenino y la forma}

El Kaddish tiene una doble virtud: Primero, muestra los avatares del reconocimiento de la alteridad en un sujeto; allí el acto del "señor maestro" permite dejar a un lado el significante 'judío'y renueva el lazo social. En segundo lugar, Kaddish por el hijo no nacido difiere -en cuanto a la forma- de Sin destino, si bien, el drama de la alteridad del judío, está presente en ambos, y seguramente, los dos textos buscan una salida distinta de aquella que llevó al suicidio a otros sobrevivientes de los campos de concentración.

Del Kaddish resalta la forma, que evidencia mejor el exilio creador que -según el escritor- es "el rostro más real de la vida"; no obstante esa expresión, ese rostro no es una imagen; como tampoco lo es el acto del "señor maestro", que, empero, también crea una manera, una forma-de-vida en un momento.

Insistamos en la distinción entre imagen y forma: Lo imaginario, recordémoslo, se relaciona con la significación. En su texto sobre la ideología, Zizek enfatiza que la homología entre Marx y Freud es haber coincidido en no dejarse seducir por el contenido (significación) y dedicarse a develar el secreto de la forma. Marx se aplica a develar qué determina la forma de las relaciones sociales y decanta un goce que formaliza con el cálculo de la plusvalía; mientras Freud oye en la forma del sueño un 
rébus que obedece las leyes del significante y descubre el motor que lo produce: el deseo inconsciente, un goce no dicho. ${ }^{49}$

La forma es pues, manifestación explícita del síntoma, estructura en la cual no todo es significante, si bien se relaciona con él y con la articulación que hace posible una significación -imaginario- como efecto secundario. La experiencia creadora es forma más que imagen, en tanto renuncia, destituye o cuestiona la significación, donde lo femenino cede espacio a lo real, a lo que no tiene sentido, en una experiencia de exilio y pérdida, ahí habita el poeta.

Pero esa experiencia creadora del poeta no es la experiencia secundaria del lector o espectador, que se aproxima a percibir y eventualmente completar la obra. Para el espectador, la obra puede quedar en el plano de lo sensible, de la significación o la imagen, de la actuación o del objeto; en todo caso como 'presentación'.

Kaddish por el hijo no nacido es radicalmente poético, objeta el género de la novela, se sitúa en otro polo, donde la obra está más próxima al tiempo mismo de la creación. El acto creador es logrado, precisamente cuando suspende la significación, hace música y silencios de la significación. Esa suspensión se evidencia con fuerza en los apartes poéticos, donde prima la experiencia que rompe la lengua: crea una nueva y extranjera, que no se deja citar fácilmente.

El poema como tiempo del sujeto es forma que no regresa, si no se la atrapa después será otro poema, nunca el mismo. El poema viene solo, es tiempo y experiencia de un empuje, que si bien puede producir pródromos y anunciarse durante un cierto lapso, se impone de pronto y demanda ser ejecutado en acto. El poeta generalmente cede, de lo contrario, 'eso' -que en cierto modo dicta su forma- huirá. Luego, ya no podrá reencontrarla, puesto que no es una 'forma pensada', es acto y no significación, una forma de experiencia, un estado, una manifestación de su ser que contingente y provisionalmente 'exhala una forma', constituye un hilado.

Creo que cuando Picasso dijo: "Yo no busco, encuentro", se refería a ese estado en el que lo femenino viene al encuentro del sujeto, fuera de sus búsquedas, fuera de sus cogitaciones, de su comprensión o sus cálculos hacia el mundo. El acto creador consiste pues en dejar ser, en aceptar que lo femenino dicte formas, aquellas que atestiguan su existencia. Es allí cuando aparece la alteridad, como ruptura entre el sujeto y eso singular que lo habita y se dirige al S(A [tachado]). La poética entonces es forma no especular, trayecto hacia el Significante que falta en el Otro, el síntoma como huella testimonia la existencia de lo femenino en el sujeto, cualquiera que sea su anatomía.

Constatar la presencia de lo femenino en el hombre, constituye una objeción de conciencia para imputarle sólo a los sujetos masculinos la ancestral discriminación contra lo femenino. El rechazo hacia la alteridad se explica porque tanto a mujeres, como a hombres, afecta el temor al exilio, el temor de admitir el fracaso del significante para responder por su ser. Pero insistir en ese desconocimiento obstaculiza la renovación del lazo social. Aunque el ser no pueda decirse ni el goce total sea posible, aún restan satisfacciones parciales, lo singular femenino como suplemento y... ¿por qué no?, jtambién gratos encuentros! 